\title{
Particularities of the energy management and labor market in Russia
}

\author{
Elena Ribokene ${ }^{1}$, Ekaterina Savelieva ${ }^{1}$, Marina Danilina $^{1,2,3,4,{ }^{*},}$ Nadezhda Prazdnikova ${ }^{5}$, \\ Yury Razovsky ${ }^{6}$, and Dmitry Berzin ${ }^{4}$ \\ ${ }^{1}$ Moscow University named after S.Yu. Vitte (MUIV), 2nd Kozhukhovsky proezd, 12, stroyeniye 1, \\ 115432, Moscow, Russia \\ ${ }^{2}$ Research Institute VNII of Labor, Ministry of Labour of Russia, Zemlyanoy Val, 34, 105064 \\ Moscow, Russia \\ ${ }^{3}$ Russian Economic University, Stremyanny per., 36, 117997 Moscow, Russia \\ ${ }^{4}$ Finance University under the Government of the Russian Federation, Leningradsky prosp., 49, \\ 125993 Moscow, Russia \\ ${ }^{5}$ Altai State University, Socialist pr., 68, Barnaul, Russia \\ ${ }^{6}$ Gzel'skii State University, 140155, posiolok Elektroizoliator, 67, Ramensky district, Moscow region, \\ Russia
}

\begin{abstract}
Energy saving problems are one of the most important problems of all countries, including Russia, since energy resources are used extremely inefficiently. As the vast and still small Russian experience shows, energy saving is a highly efficient and quickly implemented method of energy consumption in energy. Therefore, energy conservation is the most important area of energy policy in the new economic conditions. The basis of energy saving at the enterprise is the creation of an energy management system - an energy resource management system. Without energy management, it is impossible to talk about a systemic reduction in energy costs and the introduction of any energy-saving technologies at the enterprise. The introduction of an energy management system at an enterprise makes it possible to find and maintain a balance of optimal consumption of energy resources for a given production schedule. In the next 6 years, the domestic electric power industry will face largescale transformations associated with the renewal of fixed assets and the transition to a digital basis. The fulfillment of these tasks requires not only financial investments and technical support, but also the availability of professional personnel who can manage these transformations and implement them. The differentiated approach is needed to regulate the labor of energy workers.
\end{abstract}

\section{Introduction}

The electric power industry is a leading and basic branch of the country's economy, which creates mandatory conditions for the functioning of the vital and productive forces of the economy. The reliability and efficiency of the functioning of the electric power industry,

\footnotetext{
${ }^{*}$ Corresponding author: marinadanilina@yandex.ru
} 
the continuous supply of electricity to consumers is the basis for the stable development of the country's economy, a factor in ensuring comfortable living conditions for the population.

It should be borne in mind that electricity generation is a high-tech, fully automated process, in which hundreds of generators of power plants operate in a single energy system, the uninterrupted and efficient operation of which depends on management and highly qualified personnel.

The country's power supply is one of the components of national security. Along with the fact that electricity has its direct purpose, it is an important source of profit.

The energy consumer cycle consists of three processes - energy production, its transportation and distribution to consumers, and consumption itself. In each of these three processes, there is energy loss, which leads to an increase in energy consumption. Reducing these very costs has always been the goal of the energy company and consumers.

Recently, in order to conserve energy resources, energy-saving technologies have been widely introduced throughout the world, both in production and in energy transmission [1].

Energy saving problems are one of the most important problems of all countries, including Russia, since energy resources are used extremely inefficiently. As the vast and still small Russian experience shows, energy saving is a highly efficient and quickly implemented method of energy consumption in energy. Therefore, energy conservation is the most important area of energy policy in the new economic conditions. The basis of energy saving at the enterprise is the creation of an energy management system - an energy resource management system.

Without energy management, it is impossible to talk about a systemic reduction in energy costs and the introduction of any energy-saving technologies at the enterprise. The introduction of an energy management system at an enterprise makes it possible to find and maintain a balance of optimal consumption of energy resources for a given production schedule.

Energy management is an energy consumption management system permanently operating at the enterprise, which allows predicting and controlling the production, transportation and use of the required amount of energy resources to ensure the economic activity of the enterprise.

Energy management is a management process that involves cyclicality, sequential execution, coordination of planning and the creation of adequate management structures and mechanisms for stimulating and controlling the rational use of fuel and energy resources at the enterprise.

Energy management includes the organization of the optimal functioning and development of the energy part of any production based on the achievements of science, technology, technology. In turn, this is a systematic energy audit (survey) of the main and auxiliary production, the development of specific recommendations and measures to save energy with the determination of the expected and required funds, responsibility for the implementation of the energy conservation policy at the enterprise, the study of achievements in the field of energy-saving technologies, the development of their programs implementation in production with justification of the economic feasibility of energysaving measures, study and assessment of the results achieved [1,2].

Energy management also includes rationing the consumption of energy resources; development of standards for rational fuel consumption *, rational heating, cooling, heat transfer, prevention of heat loss, use of secondary energy resources, reduced: electricity losses in networks, etc.

Energy management is, firstly, not a one-time event, but a constant, painstaking longterm (payback of energy saving programs is not as fast as in purely commercial projects) work on the preparation of some programs, execution and development of others. 


\section{Materials and methods}

On the basis of the content analysis method the authors analyse the application of energy management. The task of the first degree in management is the streamlining of activities, that is, bringing things to a position where each organizational element works synchronously, in accordance with new tasks. The case concerns organizational rules, formal systems, a balanced structure, where responsibility is associated with rights, the degree of risk with potential profit, the management system - with the types of intracorporate relationships.

The business environment of an energy company includes investors, suppliers of fuel and material and technical resources, intermediaries, competitors, regulators, the public and public organizations. The energy business is also influenced by the legal framework, market conditions, political, social, cultural and many other factors.

It can be said that the factors affecting energy companies are more numerous than those of companies in other industries.

Analysis of external factors also shows a high instability of the business sector. Based on this, in order to identify the factors that support and hinder commercial success, regular analysis of the business environment becomes relevant. The concept of strategic behavior of an energy company means its activities in the field of management. It is aimed at constantly monitoring changes in the business environment and making adjustments to production that make it possible to timely influence a potential hazard [3, 4].

Strategic decisions are most often associated qualitatively with a new task that the market puts forward and require radical changes in production. The main goal of the strategy is to create conditions for adapting the activities of the energy company in a constantly changing business environment. The strategy development process between owners and managers is carried out by agreement as a result of gradual decisions.

Stakeholder assessment is a significant element. The task of strategic analysis is to obtain relevant information, by determining the real skill of a particular subject, to assist or interfere with the solution of important tasks $[3,4]$.

In the modern world, changes in the business environment are becoming more and more accelerated, which shortens the adaptation time and, accordingly, increases the complexity of the problems faced by energy companies. The more complex the problem, the longer it takes to solve it.

In the production of the electric power industry, as in the natural monopoly industry, the management functions are assigned to the state regulation of the industry. There has been a long debate about the essence of regulation. Ultimately, regulation is nothing more than the establishment of a certain order to achieve the desired goal. And the regulation of the economy implies such an impact on the economy on the part of state administrative bodies, which should ensure the achievement - the preservation of current processes at a certain level. In a centralized economy, this is mainly carried out by directives, and in a market economy, mainly by using market mechanisms. The need for regulation has arisen in a market economy environment and is driven by market failures. In particular, the market economy makes the imbalance of macroeconomics, crises of overproduction and zigzags of development indispensable. In a market economy, competition itself reproduces monopoly. The main goal of state regulation of the economy is to achieve economic stability, efficiency and justice in the country. Such monopoly can influence the energy labor market as well $[3,4]$.

The energy labor market is characterized by low elasticity. First, energy is one of the main life-supporting sectors of the economy and therefore is less susceptible to crisis influences than others. Secondly, the energy sector employs mainly rare technical specialists with high qualifications. 
Secondly, the energy sector employs mainly rare technical specialists with high qualifications. The supply of such specialists on the market is extremely limited and employers are ready to take measures to retain such specialists even in unstable economic conditions. At the same time, the energy sector is one of the most attractive industries for specialists with an engineering education, which explains the consistent growth in the number of applicants applying for work in this area.

In the next 6 years, the domestic electric power industry will face large-scale transformations associated with the renewal of fixed assets and the transition to a digital basis. It is planned to attract about 1.5 trillion rubles of private investment to renovate the domestic electric power industry. All over the country, power systems should go digital. With the help of the so-called distributed generation, it is necessary to solve the issue of power supply to remote areas $[3,4]$.

The fulfillment of these tasks requires not only financial investments and technical support, but also the availability of professional personnel who can manage these transformations and implement them. However, employers often note the lack of universal specialists - professionals who understand the production process from start to finish and, as a result, are able to improvise when solving a problem that goes beyond the template. A differentiated approach is needed to regulate the labor of energy workers.

\section{Results}

The problem of regulation is especially relevant in the context of the existence of a natural monopoly. Regulation of monopoly, including natural monopoly by the state, is an activity that is aimed at suppressing the negative results of monopolization and consumer protection. In the energy sector, the purpose of regulation is to create and implement rules that are as close as possible to market relations. The regulatory mechanism should consider the interests of both consumers and producers. The regulation of artificial monopolies limits the freedom of action of the supplier and causes economic demotivation. And regulation of natural monopolies makes society as privileged as possible and sets minimal taxes in a competitive environment. The purpose of regulation is to bring the conditions of activity of a natural monopoly closer to the conditions of a competitive market.

The goals and objectives of regulation imply an increase in the efficiency of the functioning of monopolies. From this point of view, it should delimit rights and obligations between the structural units of the industry, create such legal frameworks that will ensure the introduction of market relations, attract local and foreign investment and create a competitive market for products.

As a result, it should be noted that the characteristic features of management in the electric power industry follow from its specifics. And these features are concentrated as in the main representative of natural monopoly - in government regulation.

\section{Discussions}

The first prerequisite for the emergence of energy management is considered a law adopted in 1965 in the UK, which regulated the thermal performance of erected structures. Meanwhile, in the USSR, at the Congress of the CPSU, the need to reduce energy consumption per unit of production was actively discussed, but, nevertheless, no significant measures were taken either in the USSR or in Great Britain $[5,6]$.

The second stage was associated with the well-known Arab-Israeli conflict, which resulted in a sharp jump in oil and gas prices. Accordingly, the cost of heat and electricity has grown dramatically and reached record levels. This made many states seriously think 
about the adoption of a number of decisions related to the development of programs to save energy and resources. The result of these decisions was a reduction in energy consumption in many industrial sectors and, most importantly, the development of a legislative framework that provided for a reduction in energy consumption.

The oil crisis, even after its end, forced scientists of the world to work hard on research in the field of energy conservation, energy institutes were created, which do not stop their work today.

Another energy crisis occurred in 1991, following the US Desert Storm operation against Iraq. It was then that the program of standards and predecessor standards of modern ISO 50001, BS EN 16001 was created and launched [5, 6].

The set of measures envisaged by energy management covered the replacement of incandescent lamps with energy-saving ones, the introduction of new, more economical technology with mandatory labeling for the consumer, and more.

All this, of course, contributed to the emergence in June 2011 of the international standard ISO 50001, BS EN 16001, which provided for the main provisions of energy management. According to experts, this standard will have a positive impact on as much as $60 \%$ of all energy consumed in the world.

The practice of modern technological development has shown that reducing the energy consumption of products is based on the introduction of modern technologies and energy management standards. Increasing energy efficiency is not only a technical problem requiring technological solutions, but also a management problem. To solve this management problem, the international standard ISO 50001: 2011 was developed $[5,6]$.

The main idea of solving the management problem of increasing the level of energy efficiency is the consistent application of a systematic approach to energy management. Thus, additional opportunities for increasing the level of energy efficiency can be obtained based on the application of the standard PDCA methodology (Plan-Do-Check-Act), inherent in all well-known international standards (ISO 9001, 14001, etc.). Additional arguments that explicitly demonstrate the benefits of EMS follow from the opposition of the systemic and non-systemic approaches to energy management:

- Analysis of all aspects affecting energy efficiency, as well as continuous improvement;

- Business processes related to energy management are clearly defined and auditable by both internal and external auditors, including the possibility of certification.

- Continuous and planned energy management process with defined comparison parameters (baselines) for achieved results and documented energy goals;

- A global best practice approach that ISO continues to improve.

The problem of technical re-equipment of enterprises and reconstruction is typical not only for Russia, but also for many countries with a continental type of climate. In the EU countries, solving energy problems is one of the priority tasks. A typical example is the development of the Scandinavian countries. In accordance with the plans for the development of energy in the Scandinavian countries in the next decade, it is assumed that the increase in the level of energy efficiency through investments in equipment and technology is comparable to the increase in the level of energy efficiency as a result of measures related to the implementation of an energy management system.

\section{Conclusion}

To conclude, energy today is no longer separate and isolated. Instead, energy solutions are becoming more complex, interdependent and dynamic. Therefore, the role of energy management in a modern enterprise is high. It plays a significant role in improving economic efficiency and environmental safety. This is a complex structure of ideals, 
scientific knowledge, political priorities, practical strategies and mechanisms for planning, regulating and implementing all types of human activities in order to ensure ecological and economic stabilization. Energy management goals should be achievable, realistic and appropriate to the conditions of environmental and economic security. Its main task is to conduct a comprehensive analysis of energy consumption and, on its basis, to carry out energy-saving measures at the enterprise. Regional, municipal programs in the field of energy saving and energy efficiency should contain:

1) the values of target indicators in the field of energy conservation and energy efficiency, the achievement of which is ensured as a result of the implementation of the corresponding program;

2) a list of measures to save energy and improve energy efficiency with an indication of the expected results in physical and value terms, including the economic effect from the implementation of the corresponding program, the timing of these measures;

3 ) information on the sources of financing for energy saving and energy efficiency measures, indicating separately budgetary (if any) and off-budget (if any) sources of financing for these activities.

\section{References}

1. Energy Management, A comprehensive guide to controlling energy use, Carbon Trust (2013)

2. D. Rodrik, C. Sabel, Industrial Policy for the Twenty-First Century (2004) http://www.vedegylet.hu/fejkrit/szvggyujt/rodrik_industrial_policy.pdf

3. D.O. Skobelev, Environmental Industrial Policy In Russia: Economic, Resource Efficiency And Environmental Aspects, International Multidisciplinary Scientific GeoConference SGEM 19, 5.3, 291-298 (2019)

4. CEFIC: Facts and Figures of the European Chemical Industry, https://cefic.org/app/uploads/2018/12/Cefic_FactsAnd_Figures_2018_Industrial_BRC HURE_TRADE.pdf

5. T. Guseva, et al. Integrated Pollution Prevention and Control: Current Practices and Prospects for the Development in Russia, Proceedings of the International Multidisciplinary Scientific GeoConference Surveying Geology and Mining Ecology Management, SGEM 14, 391-398 (2014)

6. T.V. Guseva, K.A. Shchelchkov, A.Yu. Sanzharovsky, Ya.P. Molchanova, Best Available Techniques, Energy Efficiency Enhancement and Carbon Emissions Reduction, International Multidisciplinary Scientific GeoConference SGEM 19, 5.1, 63-70 (2019) 